\title{
A Deep Analysis of Applications and Challenges of Wireless Sensor Network
}

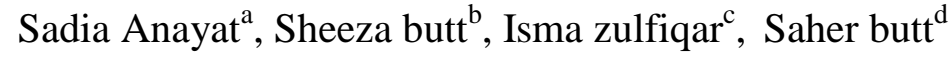 \\ ${ }^{a, b, c, d}$ Govt College Women University, Sialkot, 51040,Pakistan
}

Received: 29 April 2020; Accepted: 13 May 2020; Published: 08 June 2020

\begin{abstract}
Wireless sensor network refer to a community of a spatially dispersed and allocated sensors to track, record the enviromental physical conditions and to coordinate the collected information at a central point. WSN are becoming increasingly important with their wide range of business applications. WSN are being used in multiple fields such as health care, agriculture, systematic observation and condition based serviliance. WSN contain multiple sensors and because of features of implementing nodes, protection and authenticity, wireless sensor network become more complex. Security has drawn much attention in WSN in the last few years. But the transmission work done by sensors, is typically critical because there are large ammount of data and sensor devices are limited. Due to small number of sensers, the system is vulnerable to multiple attacks. The basic goal of this paper is to highlight the areas where the WSN is being used and multiple challenges to wireless sensor network. The multiple attacks and challenges to WSN are mentioned in this study. This research shows that although there are many challenges to WSN but still the use of wireless sensor network in multiple field such as agricultural and healthcare helps a lot to improve the efficiency, quality and performance of the those areas.
\end{abstract}

Index Terms: Wireless Sensor Network, Agriculture, Sensor, Ad-Hoc deployment.

(C) 2020 Published by MECS Publisher. Selection and/or peer review under responsibility of the Research Association of Modern Education and Computer Science

\section{Introduction}

Wireless sensor network refer to a community of a spatially dispersed and allocated sensors to track, record the enviromental physical conditions and to coordinate the collected information at a central point. The latest evolution in wireless transmission and electronic have enabled the design of less costly and cross functional

* Corresponding author

E-mail address: cssadiaanayat@gmail.com 
sensor nodes which have small size and transmit unbounded in small distances. There are a lot of sensors in sensor system which are thickly implemented within or near to circomstance[18]. The small sensors are capable enough to support the IP protocol stack because of the fast development in electronics. WSN are becoming increasingly important with their wide range of bussiness applications. With the major progress in the area of fixed devices and sensor technology, wireless sensor network consists of multiple sensors that detect, actuate and relays the collected data. Small sensor nodes are anable to supportIP protocol stack because of fast development of electronic. WSN are used in multiple application such as health care, agriculture, systematic observation and condition based serviliance. Latest advance in wireless transmission technology have allowed the production of low cost and multi functional applications in industrial, agricultural and enviromental sectors[17]. The WSN is categories in two types: infrastructured and infrastructureless. The infrastructure network comprise a wireless node with a backbone network. Network without infrastructurecontain scattered, isolated, dynamic topology and less energy network nodes.

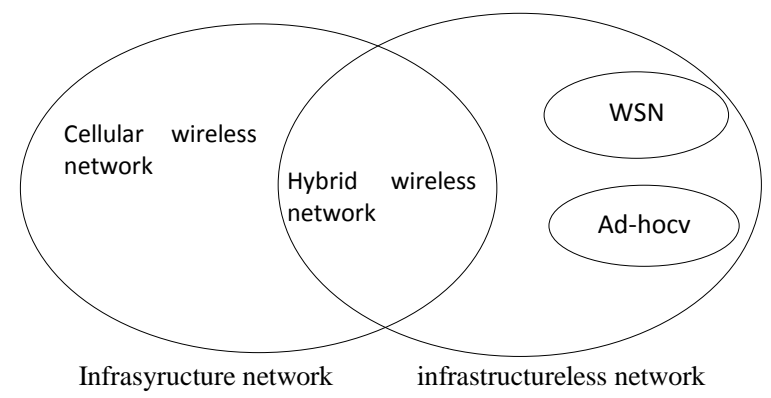

Fig. 1. Categories of WSN

The WSN's ability nothing short of groundbreaking. In near future, it will impact every facet of our life. WSN is mostly used in health, enviromental, military, and a lot of other fileds. The irrigation system in agricultural field is maintained by fuzzy controller with WSN[26]. A mixture of outlying high and low resolution sensors is used to correct the areal control. It can also be used for monitoring different framework in agricultural system. WSN is commonly used in multiple military activities such as tracing the opponent moves and protecting the army from attack. It can also be used to improve the quality oh health care system. WSN have specific features such as sensor nodes inaccuracy and space limitations, extreme energy and processing posing multiple latest challenges in creation and implementation of wireless sensor network such as big size, power limitations, the amount of stored data, manage remotely, unreliable transmission, scaleability, Ad-hoc deployement, letancy, Missing central supervisor and unstable climate. Because of features of implementing nodes, protection and authenticity, wireless sensor network become more complex.

The main purpose of this paper is to discuss the applications and challenges in WSN. This study has been conducted to identify the areas where the wireless sensor network is being used and how it can improve the quality of different field such as health, agricultural, military etc. As compare to conventional neural network, there are multiple constraints in WSN. The basic goal of this paper is to address the multiple challenges to WSN. The whole research drawn a conclusion that the use of WSN in multiple systems can improve the performance of that systems drastically.

\section{Background}

Throughout the cold war to dig up and route Soviet sub marines some network sensors were developed by the US. On the back of the vehicle it is made up of a single computer which provide its functionality on three processor that was charged by a noiseless generator. For transmission the nodes used the microwave radios $[1,2]$. On the bottom of the ocean a technique of acoustic was put down at strategic locations. The united state also 
define a network for air protection throughout the same time. In the year 1965 "Nanotechnology" is an innovation of late Richard Feynman ,who is Nobel laureate in physics. For the evolution of functional materials, evolution of product and structure of procedures and instrument for the safety of food and their biosecurity has a remarkable effect in the industry of food[3]. In the initial 1980's DARPA introduce a wireless network. Many inexpensive sensing nodes were spread and they also refined data collectively with the Distributed Sensor Network[4]. To track the lowing aircrafts the Massachusetts Institute of Technology begin expand a DSN in the mid 1980. Microphones were lay out in the form of an array and were also used for sensing. Mobile vehicles processed the acoustic signals which can be used as nodes. LPWI Micro-sensor is one of the major outcome of the WINS project which is developed in 1996. This spruce structure was locate on the CMOS chip which unified various sensors, interfaces of circuits, processing of digital circuits and wireless chips. LEACH is assemble based protocol that make us use randomization revolving of cluster base stations to evenly assign the freight of energy between the network sensors was proposed by W. B. Heinzelman, A. Chandrakasan, and H. Balakrishanan in 2000[5]. The university of California at Los Angeles introduce the idea of Wireless Integrated Sensors with the participation of Rockwell Science Center[6]. A new technique PEGASIS was introduce in which every vertex sense the data in chain and also receive the data from its predecessor and fuse the data that is received with predecessor data and then transmit it to the next chain[7]. In the agricultural and food industry the department of agriculture firstly label the application of nanotechnology in 2003. The augury is that the nanotechnology will convert the whole food industry and change the industry develop the food, packaged the food and also the way industry consumed the food. While giving the good lifespan for the first node REDAP extend the lifespan of last node in the system and its power aware system give the access of near optimal lifespan of the first node and also decreased the lifetime of last node[8]. A survey of new development in wireless sensor technology in the industry of food was present by Ning Wang at al[9]. In 2010 a Tree based clustering system was proposed in which all the distributed sensors build a analytical tree. And in this analytical tree the data is passed through a frond node to its parent node[10]. For the arrangement of the WSN a faultless node localization in the censorious requirements[11]. All the time WSN grabs the awareness of telecommunication world. They also guarantee multiple application like controlling and monitoring of traffic. Most of these applications assemble there data from sensors that are related with sensor place and it is considered senseless without facts about the location of its own origin[12].

\section{Related Work}

The following studies shows the multiple applications and challenges of WSN.

In the paper[13], the Radio Frequency Identification and Wireless Mesh Sensor Network technologies were used in agriculture field. By developing an mechanical IOT compound for irrigation system in agriculture they introduce the technology which applied in RFID and $2.45 \mathrm{GHz}$ to assist the WSN. By using this approach the major benefit is that usage of water can be reduce maximum 50\%[13].

To examine the level of humidity and temperature at specific time, the labors were need to visit the greenhouse. This procedure is time devour and also take the huge attempt. This study is focused on developing such system in agricultural greenhouse that can remotely control and monitor the level of humidity and temperature with the help of WSN. They use the SMS , GSM and wireless sensor technology which show the development such system which is very cost effective[14].

In the study[15], moisture content is designed by using value of soil for a wireless sensor network to instinctively irrigate the crops. When the soil is dry according to need of the gravity feed drip irrigation is operate using a relay on solenoid which is set on the content less than $60 \%$. XBee technology send the data in the form of frames and analysis of these frames is necessary in future we design a system which also perform of analysis on these receiving frames[15].

This paper is focused on monitoring framework of greenhouse with the help of WSN. In the last ten years, enormous advancement in technology have been done for the growth of agricultural system. The very pivotal situation for former is monitoring and the control of bumpy distribution of rain water which is not equally 
distribute to all the crops. Greenhouse technology is the good solution, all the frameworks of greenhouse require a deep analysis to choose the correct method. They use Wireless Sensor Network for monitoring frameworks of greenhouse[16].

The main motive of this work is to control the areal correctly with the help of high and low resolution nodes by using WSN. The local administration have decided to test system of original air pollution and study an approach which is suitable for gaining the supplementary data on human vulnerability to Co, O3 and NO2. Pollutants attentiveness in urban areas depend on season and time and locality of particular resources. A mixture of outlying high and low resolution sensors is used to correct the areal control[17].

WSNs obtaining the lot of significance because of huge scale of commercial applications in health care, industrial level and in home. Multi-vendor diversified sensor are locate. In WSNs domains and economic interest of multiple vendors in WSN make it complex for combine WSN due to the harsh directorial control over WSN domain. Virtualization in WSN is very effective in home level, rock sliding and monitoring of patient in hospitals[18].

A system was introduced to control the water wastage by using WSN. Towards the water conservation the notion of Fuzzy logic was inaugurate with the help of implication during the last ten years. This system could control the wastage of water using the wireless sensors. Control the efficiency of irrigation this system introduce the soil moisture, sensor for temperature using the fuzzy approach for irrigation. This system provide the huge optimization of resources[19].

The focal point of this paper is development of wireless sensor on the environment of agriculture which will be used for monitoring environment and also conclude the suitable environmental frameworks which is necessary for high capitulate the production of crops on the provided farmland. wireless sensor consume the lowest energy and cheap cost for collecting the data in agricultural domain[20].

The provocation to wireless sensor network are highlighted in this paper. WSN is a coming out technology in civilian areas and military areas that assure a huge range of future application. These wireless nodes not only have the capability of communication but they also provide data processing. Many hardware constraints present the many challenges in the development of network protocols and software development that are design for network sensor. The major focus in the WSN approach is how to give the highest lifespan to network system and hoe to provide the immovable communication and how to provide the maximum storage[21].

A system was developed to instinctively control the framework of soil by merging hardware and software. WSNs are concede as a powerful system in term of collecting the and processing data in the domain of agriculture by using less energy and using low cost equipments. The transformation of data is done by using the $\mathrm{Wi}-\mathrm{Fi}$ router. This system is also used in greenhouse environment[22].

WSN is a coming out technology around the world and it is used for observe multiple framework in agricultural system. In this paper, which is connected to monitoring system in agriculture,monitoring of pest disease and the mechanism of controlling different pest, is reviewed using WSN. They provide technological and non -technological and non-segregated solution for analysis and classification of pest. This system will reduce the burden of the farmer[23].

Over the last ten years there have been scores of scandals and happening involving epidemic of the Food Supply Chain which has void consumer confidence and limitless financial, political and health costs. Sensor Network can perform a key role in providing the industry with the help of an automated software that will help to avert the contagion of the food supply chain[24].

The energy consumption challenge is the main focus of this paper. WSNs consist of huge amount of arbitrary deployed nodes of sensor. These sensors perform three basic operation of sensing, computation and communication. The wireless sensor face the challenge of energy conservation. For productive applications of finite power supplies is also highlight which is finest to the WSNs[25].

In this modern era, every passing day disclose a new invention to the world. With the usage of remote control system, we can perceive and control system. A system was developed and implemented which can control the sensor of temperature LM35, ADC0804 and also the hardware. This system is workable for any live stock environment. In future by using different type of sensor the environment of humidity is also control and 
manage[26].

In the crop field, monitoring of micro climate is need of time. In this paper, a system was designed for storing and measuring environmental data. s This system is located in three continents, it collect data from WSNs and transform it physically at different locations[27].

\section{Applications of WSN}

WSN are becoming increasingly important with their wide range of bussiness applications. It is used in multiple field such as health care system, water system, military and agricultural. Much research has been done on the development of systems and tool which work with WSN and improve the quality of that specific area.

Table 1. Application of WSN in multiple fields

\begin{tabular}{|c|c|c|c|c|}
\hline Field & Model & $\begin{array}{l}\text { Purpose of } \\
\text { proposed Model }\end{array}$ & Description & Contribution \\
\hline Enviromental & $\begin{array}{l}\text { Creation of } \\
\text { Public-Private } \\
\text { combined WSN } \\
\text { for increased } \\
\text { effectiveness of air } \\
\text { standard }\end{array}$ & $\begin{array}{l}\text { A test of latest air } \\
\text { pollution control } \\
\text { systemd combined } \\
\text { with one was } \\
\text { tested to research a } \\
\text { suitable method } \\
\text { for collecting } \\
\text { furthur information } \\
\text { on human } \\
\text { submission to } \\
\text { NO2, oxigion and } \\
\text { carbon monoxide }\end{array}$ & $\begin{array}{l}\text { An amalgamayion of high } \\
\text { and low resolution sensing } \\
\text { nodes aimes to amend isal } \\
\text { regulation, identifing the } \\
\text { storage and duration } \\
\text { variation of all micro } \\
\text { enviroments in intra urban }\end{array}$ & $\begin{array}{l}\text { Small pollotants will also be } \\
\text { monitored in some case } \\
\text { studies. }\end{array}$ \\
\hline \multirow{3}{*}{ Agriculture } & $\begin{array}{l}\text { Control the } \\
\text { parameters of } \\
\text { Green house using } \\
\text { WSN }\end{array}$ & $\begin{array}{lr}\text { PSoC } & \text { was } \\
\text { introduces } & \text { and } \\
\text { analyzed as } & \text { WSN } \\
\text { part to track and } \\
\text { manage different } \\
\text { Green house } \\
\text { variables }\end{array}$ & $\begin{array}{l}\text { Automatic tracking and } \\
\text { maiantaing the variables of } \\
\text { green house. }\end{array}$ & $\begin{array}{l}\text { Process in less power with } \\
\text { small complexity and good } \\
\text { green house authenticity. }\end{array}$ \\
\hline & $\begin{array}{l}\text { Agricultural } \\
\text { parameter } \\
\text { monitoring }\end{array}$ & Crop monitoring & $\begin{array}{l}\text { Its hardware and software } \\
\text { based model use to control } \\
\text { the soil parameter } \\
\text { automatically }\end{array}$ & $\begin{array}{l}\text { The multiple sensors such as } \\
\text { gass, temp are monitored and } \\
\text { microcontroller are used to } \\
\text { recieve the data from sensors. }\end{array}$ \\
\hline & Pest detection & Pest monitor & $\begin{array}{l}\text { The methodologies used for } \\
\text { controlling the pest in crops } \\
\text { are compared on the base of } \\
\text { multiple parameters. }\end{array}$ & Pest deseases are monitored \\
\hline Military & $\begin{array}{l}\text { WSN applications } \\
\text { in military }\end{array}$ & $\begin{array}{l}\text { A suitable sensor } \\
\text { node in military } \\
\text { help strengthen the } \\
\text { preparedness of } \\
\text { troops and shall } \\
\text { the response time }\end{array}$ & $\begin{array}{l}\text { With reduced man power } \\
\text { and enhanced performance, } \\
\text { industrial comples and } \\
\text { manufacturing facilities can } \\
\text { be secured. }\end{array}$ & $\begin{array}{l}\text { A suitable sensor node Offers } \\
\text { clear image of war in real } \\
\text { time and a better } \\
\text { understanding of situation }\end{array}$ \\
\hline $\begin{array}{l}\text { Health care } \\
\text { system }\end{array}$ & $\begin{array}{l}\text { Real time health } \\
\text { care monitoring } \\
\text { systems }\end{array}$ & $\begin{array}{l}\text { The } \\
\text { microcontroller } \\
\text { use to test the } \\
\text { patient condition } \\
\text { by scanning } \\
\text { medical sensors }\end{array}$ & $\begin{array}{l}\text { The purposed model's } \\
\text { results are accurate in } \\
\text { scanning and monitoring }\end{array}$ & $\begin{array}{l}\text { The purposed model is } \\
\text { compared with other } \\
\text { recommended models and } \\
\text { results shows that it is better } \\
\text { than others. }\end{array}$ \\
\hline
\end{tabular}




\begin{tabular}{|c|c|c|c|c|}
\hline Entertainment & $\begin{array}{l}\text { A preparatory SN } \\
\text { based brilliant } \\
\text { structure of light } \\
\text { control which is } \\
\text { used for } \\
\text { production of } \\
\text { media and } \\
\text { entertainment }\end{array}$ & $\begin{array}{l}\text { a individuals } \\
\text { feature of } \\
\text { illuminator } \\
\text { linchpin on } \\
\text { sensing solo is } \\
\text { that is enclosure } \\
\text { loop from light } \\
\text { sensing to sway } \\
\text { lighting }\end{array}$ & $\begin{array}{l}\text { To assure the high } \\
\text { production light sensing } \\
\text { condition of entertainment } \\
\text { and media production } \\
\text { applications, the system uses } \\
\text { the illuminate which is a } \\
\text { multi modal and high } \\
\text { constancy light sensor } \\
\text { elements well suited to } \\
\text { wireless sensor networks }\end{array}$ & $\begin{array}{l}\text { We show that the illuminator } \\
\text { deal with multiple high level } \\
\text { users limitation and create } \\
\text { finest light animation profile }\end{array}$ \\
\hline $\begin{array}{l}\text { Transportation } \\
\text { and Smart } \\
\text { Logistics }\end{array}$ & $\begin{array}{l}\text { For smart logistics } \\
\text { and transportation } \\
\text { WS nodes called } \\
\text { the smart points }\end{array}$ & $\begin{array}{l}\text { Smart points detect } \\
\text { the contexture } \\
\text { surroundings and } \\
\text { when particular } \\
\text { events are } \\
\text { encounter they } \\
\text { generates alarms }\end{array}$ & $\begin{array}{l}\text { they compute the endure } \\
\text { shelf life of the } \\
\text { biodegradable goods they } \\
\text { move with, when the internet } \\
\text { connection is available WSN } \\
\text { accessible throughout travel, } \\
\text { the shelf-life augury and } \\
\text { connected alarms are at first } \\
\text { hand sent to a back-end } \\
\text { server }\end{array}$ & $\begin{array}{l}\text { WSN carry a unit of } \\
\text { agreement that allow support } \\
\text { for the strong operation in } \\
\text { logistic the middleware } \\
\text { provide simple combination } \\
\text { with request of third-party }\end{array}$ \\
\hline Smart Buildings & ZigBee & $\begin{array}{l}\text { by design, } \\
\text { evolution and } \\
\text { testing of sharp } \\
\text { home devices } \\
\text { control structure } \\
\text { through ZigBee } \\
\text { according to the } \\
\text { convenience of } \\
\text { chronic sunlight, } \\
\text { occupancy, } \\
\text { consolation and } \\
\text { demand of the } \\
\text { resident }\end{array}$ & $\begin{array}{l}\text { A webpage is create to assist } \\
\text { people to ingress the } \\
\text { structure, the light power and } \\
\text { the speed of fan can be } \\
\text { modified according to the } \\
\text { consolation level and } \\
\text { residents venture based } \\
\text { demand }\end{array}$ & $\begin{array}{l}\text { Upgrade user consolation at } \\
\text { an gradual cost }\end{array}$ \\
\hline $\begin{array}{l}\text { Smart grid and } \\
\text { energy control }\end{array}$ & $\begin{array}{l}\text { WSN based } \\
\text { Residential Energy } \\
\text { Management } \\
\text { strategy which } \\
\text { turnery attach } \\
\text { machines with non } \\
\text { acute modish } \\
\text { meter through } \\
\text { turnery SN }\end{array}$ & $\begin{array}{l}\text { Help to shift non } \\
\text { acute gadgets to } \\
\text { the off-peak time } \\
\text { which reduce the } \\
\text { green house gas } \\
\text { discharge }\end{array}$ & $\begin{array}{l}\text { Two way transmission } \\
\text { between usage and spruce } \\
\text { meter in our houses smart } \\
\text { grid allow a time of use tariff } \\
\text { which minimize the load of } \\
\text { peak with the help of } \\
\text { domestic machines }\end{array}$ & Minimize the usage cost \\
\hline Wildlife tracking & Hierarchical WSN & $\begin{array}{l}\text { This hierarchical } \\
\text { network is locate } \\
\text { in park which } \\
\text { examine the } \\
\text { animals behaviors } \\
\text { using some smart } \\
\text { machines which } \\
\text { contain the neural } \\
\text { network }\end{array}$ & $\begin{array}{l}\text { Model detect the behavior } \\
\text { then the detected information } \\
\text { passed to the database for } \\
\text { more treatment }\end{array}$ & $\begin{array}{l}\text { Minimize the power usage } \\
\text { and provide animals behavior } \\
\text { observation for biologists }\end{array}$ \\
\hline
\end{tabular}

\section{Challenges to Wireless Sensor Network}

As compare to conventional neural network, there are multiple constraints in WSN. Security has drawm much attention in WSN in the last few years. Because of expedients limitation, the most difficult task for these system is security of computer. Some challenges are discussed as follow. 


\section{High risk of physical attacks:}

Sensors are left unguarded after deployement and physically quick to negotiate. An opponent may insert venomous code into one or more captured sensors to trigger threats are obtain network data. The adversary can drain that transmission fall or some serious attacks are launched.

\section{Manage remotely:}

Physical interference and physical management problems are hard to find out because of remote monitoring of sensor network.

\section{3. $\quad$ Missing central supervisor:}

Sensor network must be dispered network and every sensor can operate independently without a central supervisor in network. Unless it is constructed incorrectly, it can make the company of the network complicated, weak and ineffective.

\section{Unreliable transmission:}

Packet based routing technique is used by sensor network for transmission. Consequently, the communication is fundamentally unstable and connectionless.

\section{Power limitation:}

WSN are being growing every day, because all sensors are depend on power for their operations so this has been the greatest limitation in WSN and the main necessity. Even single node's failure can damage the entire network. Some systems therefor must be built to preserve the power resources.

\section{Scalability:}

A network topology is dynamic, it varies depend on the costomer needs. Every network sensor needs to be scalable so they can respond to verying network topology.

\section{Letancy:}

Letancy refer to the time that is taken by a node to detect or communicate the operations. the sensors collect the data, computer it and transfer it to the base station. In WSN, the letancy is measured by these activities and also the amount of time that a sensor take to transfer the information in high or low density network traffic.

\section{Conflict:}

Because of obstruction of data packets, the transmission is still not reliable. This is because the WSN is transmitted in nature. 


\section{Wireless communication:}

The open nature of wireless media is not much secure and thus render it endangered to different form of venomous attacks. These can be active or passive. In passive attacks, the opponant steal the information within the network. In active attacks, the attacker change and insert the packets in the network.

\section{Ad-hoc deployement:}

The sensor nodes are dynamically distributed and have no det topology. The Ad-Hoc design of WSN mean that there is no definable standard design. Because of its high node versatibility, the topology of networks still concern to very. So security system should be enable enough to work in such a verying enviroment

\section{Hostile Enviroment:}

Another persuasive consideration is hostile enviroment where the sensors are implemented. WSN are susceptible to numerous security threats because of broadcast nature of communication channal. Furthermore, the nodes are not implemented in safe enviroment. An opponent may insert venomous code into one or more captured sensors to trigger threats are obtain network data. To safety reseachers, the the extremely aggressive climatereflect demanding approach.

\section{Security:}

Security is one of the key issue in WSN. As in wireless sensor network, the data transmit via air, so wireless signals are accessable tp everyone. So anyone can control and participate in communication, unknown access to and denial of service DoS attacks.WSN is being used in many applications which involve information that should be confidential and secure. Specially for the applications deal with the top secret information such as military applications. So security of information in multiple fields is a major concern in WSN.

\section{Calculation cost:}

Unreliable output can resulted from the deployement of sensors without sufficient coverage. Sensing coverage if one of the most significant factor for service quality in WSN. A distributed approach for calculating coverage level is needed.

\section{Attacks on WSN}

Wireless sensors network are composed of multiple sensor nodes which track the enviromental conditions continuously. A lot of operations are performed by sensor nodes such as signal processing, computing and self configuring network to extend the network braodcasting and improve its expandability. The sensor nodes are used for sensing and transmitting of information about the sorrounding. The transmission work is typically critical because there are large ammount of data and sensor devices are limited. Due to small number of sensing devices, the network is vulnerable to multiple attacks. Typical protection techniques do not extend to wireless network sensor, as they are typically heavy and node are small. Because of multi hop nature of communication media, the WSN are vulnerable to large range of privacy attacks[27]. There are a lot of issues in network layer:

i. To optimize the energy usage, a versatile framework is needed to conduct the route discovery and maintenance in network layer.

ii. Route maintenance is needed when a route breakage is found in routing protocol. 
iii. Route concord will be a diverse nature. All nodes should be unique in the term odf transmission, processing and power.

iv. Energy quality is critical criterion.

v. Some nodes may generate the same information. So the routing protocol should use mechanism to cover such redundancy in order to boost enerdy and bandwidth.

Table 2. Layer based attacks

\begin{tabular}{|c|c|c|}
\hline Layers & Attacks & Security perspective \\
\hline Network layer & $\begin{array}{l}\text { Sybil attack } \\
\text { Wormhole attack } \\
\text { Sinkhole } \\
\text { Flooding }\end{array}$ & $\begin{array}{l}\text { Authenticate } \\
\text { Authorization } \\
\text { Identity certification }\end{array}$ \\
\hline Application layer & $\begin{array}{l}\text { Aggregation based attacks } \\
\text { Attacks on reliability }\end{array}$ & Cryptography \\
\hline Data link layer & $\begin{array}{l}\text { Jamming } \\
\text { Collision } \\
\text { Traffic manipulation }\end{array}$ & $\begin{array}{l}\text { Usage of bugs removing Codes } \\
\text { Use spread spectrum approaches }\end{array}$ \\
\hline Transport layer & $\begin{array}{l}\text { Resynchronization } \\
\text { Packet injection attack }\end{array}$ & Packet Authenticity \\
\hline Physical layer & $\begin{array}{l}\text { Denial of Service } \\
\text { Tampering }\end{array}$ & $\begin{array}{l}\text { Priority text } \\
\text { Tamper Proofing } \\
\text { Hiding, Encryption }\end{array}$ \\
\hline
\end{tabular}

Wireless network sensor is layered in shaped. This complex system vulnerabilities these network and contribute to destroy from diffirent sort of threats. Diveres threats and solution strategies are specified for each layer[28]. Now the table below displays network layer attacks on wireless sensor network, their description and comparison centered on its appraoches and their impacts.

Table 3. Classification of network layer Attacks On WSN

\begin{tabular}{|c|c|c|c|c|}
\hline $\begin{array}{l}\text { Serial } \\
\text { number }\end{array}$ & Attack & Description of attack & Detection of attack & Effect of attack \\
\hline 1 & Hello flood & $\begin{array}{l}\text { The opponent transmit the } \\
\text { hello text with solid } \\
\text { communication energy to the } \\
\text { system and pretent as a fraud } \\
\text { descent }\end{array}$ & $\begin{array}{l}\text { A packet sniffing tool can be } \\
\text { install in any network system } \\
\text { to detect the attack. If system } \\
\text { recieve the packets that are } \\
\text { not send to this. It mean } \\
\text { network is flooded. }\end{array}$ & $\begin{array}{l}\text { Complicate the route of } \\
\text { network }\end{array}$ \\
\hline 2 & $\begin{array}{l}\text { Misdirection } \\
\text { attack }\end{array}$ & $\begin{array}{l}\text { The attacker send the } \\
\text { container to the wrong node } \\
\text { and generate the loops in the } \\
\text { whole system. }\end{array}$ & $\begin{array}{l}\text { A node can be detected as } \\
\text { venomous node if node } \\
\text { increase the delay per hop for } \\
\text { maximum time. }\end{array}$ & $\begin{array}{l}\text { Deteriorate the wireless } \\
\text { sensor network efficiency. }\end{array}$ \\
\hline 3 & Sinkhole & $\begin{array}{l}\text { As compare to blackhole, } \\
\text { sinkhole is more complicated } \\
\text { attack }\end{array}$ & $\begin{array}{l}\text { One way hash chain is used } \\
\text { for detection of sinkhole } \\
\text { attack }\end{array}$ & $\begin{array}{l}\text { Differ the position of origion } \\
\text { station. } \\
\text { entice all network traffic. }\end{array}$ \\
\hline 4 & $\begin{array}{l}\text { Packet drop } \\
\text { attack }\end{array}$ & $\begin{array}{l}\text { The attacker get the all the } \\
\text { network massages but } \\
\text { doesn't forward them. }\end{array}$ & $\begin{array}{l}\text { AODV routing protocol with } \\
\text { ligh weight techniques are } \\
\text { used for attack detection }\end{array}$ & $\begin{array}{l}\text { Disturb the performance of } \\
\text { network. } \\
\text { Stop the network to perform } \\
\text { its functionality. }\end{array}$ \\
\hline
\end{tabular}




\begin{tabular}{|c|c|c|c|c|}
\hline 5 & Sock pupperty & $\begin{array}{l}\text { A vnomous node entice the } \\
\text { network traffic by showing } \\
\text { to the network, a lot of } \\
\text { identities. }\end{array}$ & $\begin{array}{l}\text { Fine grained physical channal } \\
\text { information is use to detect } \\
\text { the attack }\end{array}$ & $\begin{array}{l}\text { Enable other threats. } \\
\text { Wireless network sensor } \\
\text { disturbance. }\end{array}$ \\
\hline 6 & $\begin{array}{l}\text { Wormhole } \\
\text { attack }\end{array}$ & $\begin{array}{l}\text { The wormhole attackers have } \\
\text { strong communication tools } \\
\text { and set a better transmission } \\
\text { medium between them. }\end{array}$ & $\begin{array}{l}\text { Prob protocol is use to detect } \\
\text { the wormhole attack which } \\
\text { flood the network with } \\
\text { messages and allow all the } \\
\text { nodes to measure the hop } \\
\text { distance to the warm boot } \\
\text { node by themselves. }\end{array}$ & $\begin{array}{l}\text { Forget dispeling data. } \\
\text { Change usual massage } \\
\text { stream. }\end{array}$ \\
\hline 7 & $\begin{array}{l}\text { Selective } \\
\text { leaching }\end{array}$ & $\begin{array}{l}\text { The opponent decline to } \\
\text { progress the packet and } \\
\text { pretend as a blackhole. }\end{array}$ & $\begin{array}{l}\text { A protection strategy is used } \\
\text { which detect the attack and by } \\
\text { using multi hope } \\
\text { acknowledgements from } \\
\text { different network nodes, it } \\
\text { raise alarm. }\end{array}$ & $\begin{array}{l}\text { Text creation and packet } \\
\text { releasing. } \\
\text { Text alternation. }\end{array}$ \\
\hline 8 & $\begin{array}{l}\text { Spoofing } \\
\text { attack }\end{array}$ & $\begin{array}{l}\text { Assailant pastiche the ACKs } \\
\text { of network layers of above } \\
\text { packet. }\end{array}$ & $\begin{array}{l}\text { Smart security tool are use for } \\
\text { detection and prevention. }\end{array}$ & $\begin{array}{l}\text { Wrong wireless } \\
\text { network data. } \\
\text { Introduce } \\
\text { threats. }\end{array}$ \\
\hline
\end{tabular}

This table shows multiple the network layer attach on WSN. The description, detection and effects of those attacks are mentioned. All these attacks effect the network layer of wireless sensor network in different way. Different mechanism are used for detection of these attacks. For example; In Misdirection attack, The attacker send the container to the wrong node and generate the loops in the whole system.. The opponent decline to progress the packet and pretend as a blackhole in selective leaching but the attack can be detected by using a specific protection strategy and by using multi hope acknowledgements from different network nodes, it raise alarm. Moreover, Sock pupperty is a type of network attack which effect the network in such a way that a vnomous node entice the network traffic by showing to the network, a lot of identities. Sinkhole is more complicated as compare to the blackhile attack which Differ the position of origion station and entice all network traffic. It can be detect by using one way hash chain. The opponent transmit the hello text with solid communication energy to the system and pretent as a fraud descent in helo flood attack and a packet sniffing tool can be install in any network system for the detection of this attack.

Nutshell, multiple network layer attacks effect the network layer of WSN in different ways. There must be a mechanism for reducing the impacts of these attacks to enhance the performance of WSN. So different strategies are used first for detection of different attacks. After detection, the possible solution is applied to remove the effects of that specific attack.

\section{Discussion}

WSN refer to a community of a spatially dispersed and allocated sensors to track, record the enviromental physical conditions and to coordinate the collected information at a central point. WSN are becoming increasingly important with their wide range of business applications. WSN are being used in multiple fields such as health care, agriculture, systematic observation and condition based serviliance. A lot of operations are performed by sensor nodes such as signal processing, computing and self configuring network to extend the network braodcasting and improve its expandability. The latest evolution in wireless transmission and electronic have enabled the design of less costly and cross functional sensor nodes which have small size and transmit unbounded in small distances. It is used in multiple field such as health care system, water system, military and agricultural. Wireless sensors network are composed of multiple sensor nodes which track the enviromental conditions continuously. Due to small number of sensing devices, the network is vulnerable to multiple attacks. Because of features of implementing nodes, protection and authenticity, wireless sensor network become more complex. 
This study contribute to show that applications, attacks and challenges to wireless sensor network. Much research has been done on the development of systems and tool which work with WSN and improve the quality of that specific area. In this paper, the multiple areas where the WSN are being used are highlighted. WSN is used in military, agriculture and hospitals etc to enhance the efficiency of these fields. For example, In medical field the microcontroller use to test the patient condition by scanning medical sensors. In military system, a suitable sensor node in military help strengthen the preparedness of troops and shall the response time. Multiple attacks and challenges to WSN are mentioned in this paper. The sensor nodes are used for sensing and transmitting of information about the sorrounding. The transmission work is typically critical because there are large ammount of data and sensor devices are limited. Due to small number of sensing devices, the network is vulnerable to multiple attacks. A lot of attacks and detection methods, effects solutions of those attacks are mentioned in this study. This study shows that the usage of WSN in multiple fields help a lot to improve the quality of that specific field. It is proved from all above research that the usage of WSN's applications can bring a drastic change in the world.

\section{Conclusion}

WSN are becoming increasingly important with their wide range of business applications. WSN are being used in multiple fields such as health care, agriculture, systematic observation and condition based serviliance. The latest evolution in wireless transmission and electronic have enabled the design of less costly and cross functional sensor nodes which have small size and transmit unbounded in small distances. Thie main gioal of this paper is to flash the light on the fields where the WSN is being used. The research have shown that the usage of WSN can increase the performance and quality of multiple areas. The study give the better picture of usage of WSN and impact of using this technology. In this paper, multiple attacks on WSN are mentioned and detection techniques and solution of those attacks are also given. The challenges to WSN are highlited in detail. In this paper, it is proved that the use of WSN in multiple fields can bring a drastic change in the world.

\section{References}

[1] Wang, N., Zhang, N., \& Wang, M.,Wireless sensors in agriculture and food industry-Recent development and future perspective. Computers and electronics in agriculture, 50(1),2006,1-14.

[2] bbasi, A. Z., Islam, N., \& Shaikh, Z. A.,A review of wireless sensors and networks' applications in agriculture, Computer Standards \& Interfaces, 36(2),2014,263-270.

[3] C.I. Moraru, T.C. Lee, M V. Karwe and J.L. Kokini, Plasticizing and antiplasticizing effects of water and polyols on a meat-starch extruded matrix, J. Food Sci., 67(2003), 3396-3401.

[4] Akyildiz, I. F., Su, W., Sankarasubramaniam, Y., \& Cayirci, E.,A survey on sensor networks, IEEE Communications magazine, 40(8),2002, 102-114.

[5] W. R. Heinzelman, A. Chandrakasan, and H. Balakrishnan, Energy efficient communication protocols for wireless micro sensor networks, in Proc. 33rd Hawaii Int. Conf. System Sci., Jan. 2000, pp. 3005-3014.

[6] Perrig, A., Szewczyk, R., Wen, V., Culler, D., and Tygar, J.SPINS: Security protocols for sensor networks. J.Wireless Nets. 8, 5 (Sept. 2002).

[7] S. Lindsey and C. Raghavendra, Pegasis: Power-efficient gathering in sensor information systems, in Proc. IEEE Aerospace Conf., 2002 vol. 3, pp. 1125-1130

[8] H. O. Tan and I. Korpeoglu, Power efficient data gathering and aggregation in wireless sensor networks, SIGMOD Rec., vol. 32, no. 4, pp. 66-71, 2003.

[9] N. WANG, M. H. Wang, and N. Q. Zhang, "Wireless sensors in agriculture and food industry: Recent development and future perspective," Computers and electronics in agriculture, vol. 50, no. 1, pp. 1-14, 2006. 
[10] K. T. Kim and H. Y. Youn, Tree-Based Clustering (TBC) for energy efficient wireless sensor networks, in Proc. AINA 2010, 2010, pp. 680-685

[11] J. Graefenstein, A. Albert, P. Biber, and A. Schilling, "Wireless node localization based on RSSI using a rotating antenna on a mobile robot," 2009 6th Work. Positioning, Navig. Commun., vol. 2009, pp. 253$259,2009$.

[12] P. Kułakowski, J. Vales-alonso, E. Egea-lópez, W. Ludwin, and J. García-haro, "Angle-of-arrival localization based on antenna arrays for wireless sensor networks q," Proc. $9^{\text {th }}$ Int. Symp. Commun. Inf. Technol., vol. 36, pp. 549 - 554, 2010.

[13] Zulkifli, C. Z., and N. N. Noor. "Wireless Sensor Network and Internet of Things (IoT) Solution in Agriculture." Pertanika Journal of Science \& Technology 25.1 (2017).

[14] Aziz, Izzatdin Abdul, et al. "Remote monitoring in agricultural greenhouse using wireless sensor and short message service (SMS)." International Journal of Engineering \& Technology IJET 9.9 (2009): 1-12.

[15] Ho, Angelina MY, et al. "Solar Powered Gravity-Feed Drip Irrigation System Using Wireless Sensor Network." International Journal of Environmental Science and Development 6.12 (2015): 970.

[16] Chaudhary, D. D., S. P. Nayse, and L. M. Waghmare. "Application of wireless sensor networks for greenhouse parameter control in precision agriculture." International Journal of Wireless \& Mobile Networks (IJWMN) 3.1 (2011): 140-149.

[17] Ragazzi, M., et al. "A contribution to the development of a public-private integrated network of wireless sensors for an enhanced management of air quality." Sustainable Technology for Environmental Protection (2012): 1-4

[18] Islam, Md Motaharul, and Eui-Nam Huh. "Virtualization in wireless sensor network: Challenges and opportunities." Journal of Networks 7.3 (2012): 412.

[19] Khan, Faraz, Faizan Shabbir, and Zohaib Tahir. "A FUZZY APPROACH FOR WATER SECURITY IN IRRIGATION SYSTEM USING WIRELESS SENSOR NETWORK." Science International 26.3 (2014).

[20] Joshi, P. P., S. S. Kanade, and S. P. Joshi. "Wireless sensor network and monitoring of crop field." IOSR Journal of Electronics and Communication Engineering (IOSR-JECE) 12.1 (2017): 23-28.

[21] Gungor, Vehbi C., Bin Lu, and Gerhard P. Hancke. "Opportunities and challenges of wireless sensor networks in smart grid." IEEE transactions on industrial electronics 57.10 (2010): 3557-3564.

[22] Joshi, P. P., and S. S. Kanade. "Wireless sensors and agriculture parameter monitoring: experimental investigation." J Electron Commun Eng Res 3.8 (2017): 6-13.

[23] Azfar, Saeed, Adnan Nadeem, and Abdul Basit. "Pest detection and control techniques using wireless sensor network: A review." Journal of Entomology and Zoology Studies 3.2 (2015): 92-99.

[24] Connolly, Martin, and Fergus O’Reilly. "Sensor networks and the food industry." Workshop on RealWorld Wireless Sensor Networks. 2005.

[25] Tarannum, Suraiya. "Energy conservation challenges in wireless sensor networks: A comprehensive study." Wireless Sensor Network 2.06 (2010): 483.

[26] Khan, M. Saleem, et al. "Controlling and monitoring of temperature system for livestock." The Journal of Animal \& Plant Sciences 24.3 (2014): 969-972.

[27] Ghobakhlou, A., S. Shanmuganthan, and P. Sallis. "Wireless sensor networks for climate data management systems." 18th World IMACS/MODSIM Congress, Cairns, Australia. 2009.

[28] Maidamwar, Priya, and Nekita Chavhan. "Wormhole Attack in Wireless Sensor Network." (2012). 


\section{Authors' Profiles}

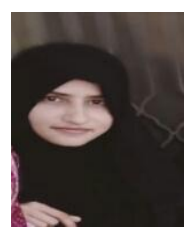

Sadia Anayat is doing her BS (Hons) in Computer Science (CS) from Govt College Women University Sialkot. She is also certified as Microsoft Office specialist. Currently she is working on research in Blochain technology and comparison between bitcoin and ethereum, cloud computing and green computing topic, artificial intelligence. Her main areas of research interest is wireless sensor network.

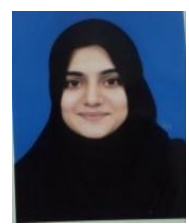

Sheeza Butt was born in Sialkot in 1999. She did her matriculation level in 2014 from, Govt. Girls Higher Secondary school Sambrial, district Sialkot in Science Subjects and her intermediate level (I.C.S) in 2016 from Superior college Sambrial, district Sialkot. Now she is doing her BS (Hons) in Computer Science (CS) from GCWU, Sialkot. She is also certified as Microsoft Office specialist. Currently she has been working on research in Blochain technology and comparison between bitcoin and ethereum topic. Her main areas of research interest are blockchian technology.

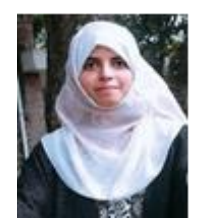

Isma Zulifqar is doing her BS (Hons) in Computer Science (CS) from Govt College Women University Sialkot. One of her paper is published recently. Currently she has been working on research as final year project in Data Diversity in Medical IoT topic. Her main areas of research interest are Cloud Computing, primary dangerous computer viruses, DataBase and Programming Languages.

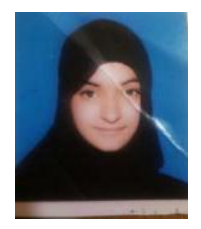

Saher Butt was born in Sialkot in 1999. She did her matriculation level in 2014 from Danish Public High School Sambrial, Sialkot in Science Subjects and her intermediate level (I.C.S) in 2016 from Superior College Sambrial, Sialkot. Now she is doing her BS (Hons) in Computer Science (CS) from GCWU, Sialkot. She is also certified as Microsoft Office specialist. Currently she has been working on research in Blochain technology and comparison between bitcoin and ethereum topic. Her main areas of research interest are blockchian technology.

How to cite this paper: Sadia Anayat, Sheeza butt, Isma zulfiqar, Saher butt, " A Deep Analysis of Applications and Challenges of Wireless Sensor Network ", International Journal of Wireless and Microwave Technologies(IJWMT), Vol.10, No.3, pp. 32-44, 2020.DOI: 10.5815/ijwmt.2020.03.03 